\title{
Alstonine as an Antipsychotic: Effects on Brain Amines and Metabolic Changes
}

\author{
Viviane M. Linck,, ${ }^{1,2}$ Ana P. Herrmann, ${ }^{1}$ Ângelo L. Piato, ${ }^{1,2}$ Bernardo C. Detanico, ${ }^{1}$ \\ Micheli Figueiró, ${ }^{1}$ Jorge Flório, ${ }^{3}$ Maurice M. Iwu, ${ }^{4,5}$ Christopher O. Okunji, ${ }^{4,5}$ \\ Mirna B. Leal, ${ }^{1}$ and Elaine Elisabetsky ${ }^{1,2}$
}

\author{
${ }^{1}$ Laboratório de Etnofamacologia, ICBS, Universidade Federal do Rio Grande do Sul, Rua Sarmento Leite 500/202, \\ 90050-170 Porto Alegre, RS, Brazil \\ ${ }^{2}$ Programa de Pós-Graduação em Ciências Farmacêuticas, UFRGS, Porto Alegre, Brazil. Av. Ipiranga, 2752, \\ $1^{\circ}$ andar, 90610-000 Porto Alegre, RS, Brazil \\ ${ }^{3}$ Departamento de Patologia, Faculdade de Medicina Veterinária e Zootecnia, Universidade de São Paulo, USP, \\ São Paulo-SP 05508-900, Brazil \\ ${ }^{4}$ International Centre for Ethnomedicine and Drug Development, University of Nigeria, Nsukka, Nigeria \\ ${ }^{5}$ Bioresources Development and Conservation Programme, University of Nigeria, Nsukka, Nigeria
}

Correspondence should be addressed to Viviane M. Linck, vivilinck@gmail.com

Received 4 August 2008; Accepted 12 January 2009

Copyright (C) 2011 Viviane M. Linck et al. This is an open access article distributed under the Creative Commons Attribution License, which permits unrestricted use, distribution, and reproduction in any medium, provided the original work is properly cited.

\begin{abstract}
Managing schizophrenia has never been a trivial matter. Furthermore, while classical antipsychotics induce extrapyramidal side effects and hyperprolactinaemia, atypical antipsychotics lead to diabetes, hyperlipidaemia, and weight gain. Moreover, even with newer drugs, a sizable proportion of patients do not show significant improvement. Alstonine is an indole alkaloid identified as the major component of a plant-based remedy used in Nigeria to treat the mentally ill. Alstonine presents a clear antipsychotic profile in rodents, apparently with differential effects in distinct dopaminergic pathways. The aim of this study was to complement the antipsychotic profile of alstonine, verifying its effects on brain amines in mouse frontal cortex and striatum. Additionally, we examined if alstonine induces some hormonal and metabolic changes common to antipsychotics. HPLC data reveal that alstonine increases serotonergic transmission and increases intraneuronal dopamine catabolism. In relation to possible side effects, preliminary data suggest that alstonine does not affect prolactin levels, does not induce gains in body weight, but prevents the expected fasting-induced decrease in glucose levels. Overall, this study reinforces the proposal that alstonine is a potential innovative antipsychotic, and that a comprehensive understanding of its neurochemical basis may open new avenues to developing newer antipsychotic medications.
\end{abstract}

\section{Introduction}

The management of schizophrenic symptoms has never been a trivial matter, further complicated by the low adherence to treatments and the serious side effects of available drugs. Classical antipsychotics, blocking $\mathrm{D}_{2}$ dopamine receptors, lead to extrapyramidal effects related to antagonism in the nigrostriatal pathway [1], and hyperprolactinaemia due to antagonism in the tuberoinfundibular pathway [2]. In the early 1990s a new class of antipsychotics was introduced in the clinic, with the alleged advantage of causing no or minimal extrapyramidal (EPS) side effects $[3,4]$, and the resulting potential to increase treatment adherence. Unfortunately, however, it is now recognized that atypical antipsychotics often induce diabetes, hyperlipidaemia and weight gain [5-7]. For instance, patients on clozapine have a 4 times higher chance of developing diabetes, hyperglycaemia, and hyperlipidaemia than patients on classical antipsychotics [8]. The mechanisms by which these metabolic alterations are produced are not entirely understood [9].

Post marketing surveillance has shown that the socalled atypical antipsychotic drugs are indeed quite heterogeneous pharmacologically, varying in effectiveness, as well as metabolic and EPS side effects [10]. It is thought that atypical 


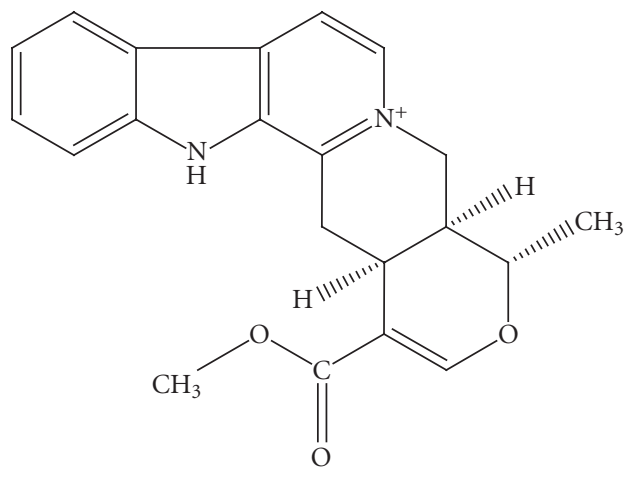

Figure 1: Alstonine.

antipsychotics fail to induce significant EPS effects due to their weakened blockade of $\mathrm{D}_{2}$ dopamine (DA) receptors combined with interactions with various neurotransmitters, especially serotonin $(5 \mathrm{HT})$ and in particular the $5 \mathrm{HT}_{1 \mathrm{~A}}$, $5 \mathrm{HT}_{2 \mathrm{~A}}$ and $5 \mathrm{HT}_{2 \mathrm{C}}$ receptors [1]. Accordingly, specific DA pathways may be modulated by serotonin receptors, depending on the presence of serotonergic receptor sub-types [11]. Given that positive and negative symptoms of schizophrenia are thought to reflect an imbalance in DA mesolimbic and mesocortical pathways [12], and the problems seen with merely blocking DA receptors, it is an attractive idea that 5 HT receptors can precisely modulate different DA pathways.

The indole alkaloid alstonine (Figure 1) was identified as the major component of a plant-based treatment given to mentally ill patients in Nigeria [13]. Alstonine shows a clear antipsychotic profile in rodents, closer to atypical than to classical agents [14]. Apparently, alstonine induces dissimilar effects in dopaminergic pathways: while apomorphineinduced stereotypy and amphetamine-induced lethality were significantly reduced by alstonine, suggesting a decrease in mesolimbic DA, alstonine reversed haloperidol-induced catalepsy, indicating that nigrostriatal dopamine transmission is not lessened [14]. Relevant for the treatment of negative symptoms, alstonine also presents anxiolytic properties, involving $5 \mathrm{HT}_{2 \mathrm{~A}, \mathrm{C}}$ receptors, and reverses interaction deficits induced by MK801 $[15,16]$.

In order to better understand the basis of alstonine's antipsychotic profile, the aim of this study was to verify alstonine effects on brain amines in mouse frontal cortex and striatum. Additionally, we examined if alstonine causes the same hormonal and metabolic changes induced by classical and atypical antipsychotics.

\section{Materials and Methods}

2.1. Plant Material. Mature fruits of Picralima nitida Stampf Th. et H.Dur. were collected by staff from the International Centre of Ethnomedicine and Drug Development (InterCEDD) in February and March 2002, in Nnewi, Anambra state, Nigeria. The plant material was identified by comparison with a voucher specimen $(\mathrm{UNN} / 83 / 07)$ at the Department of Pharmacognosy Herbarium of the University of Nigeria, Nsukka, and authenticated by Mr A. Ozioko of the Department of Botany of the same university. The fruit rind was separated, dried, and pulverized. The powdered material was successively extracted with n-hexane, methylene chloride, and methanol. Extracts were concentrated under vacuum using a rotary evaporator.

2.2. Isolation and Identification of Alstonine. Pure alstonine hydrochloride used for this investigation was isolated from the fruit rind of $P$. nitida Stampf Th. et H.Dur. (Apocynaceae). The separations were performed using $\mathrm{pH}-$ zone-refining counter-current chromatography as previously described [17]. Briefly, the experiment was performed with a two-phase solvent system composed of methyl tert-butyl ether $(\mathrm{MtBE})$-acetonitrile-water $(2: 2: 3, \mathrm{v} / \mathrm{v})$, where triethylamine (TEA) was added to the upper organic stationary phase as a retainer, and hydrochloric acid $(\mathrm{HCl})$ to the aqueous mobile phase as an eluter. The basic organic phase was used as the stationary phase and the acidic lower phase was used as the mobile phase. The separation was initiated by filling the entire column with the stationary phase using the LC pump, and then loading the sample. The sample solution was prepared by dissolving $15.0 \mathrm{~g}$ of alkaloid fraction of the methylene chloride extract of $P$. nitida in $100 \mathrm{~mL}$ of a phase mixture consisting of equal volumes of each phase. The mobile phase was then pumped into the column at $2 \mathrm{~mL} \mathrm{~min}^{-1}$ while the column was rotated at $834 \mathrm{rpm}$ in the combined head to tail elution mode $[18,19]$. The absorbance of the eluate was continuously monitored at $280 \mathrm{~nm}$ and $4 \mathrm{~mL}$ fractions were collected. The $\mathrm{pH}$ of each eluted fraction was measured with a $\mathrm{pH}$ meter and fractions were dried using a Speed Vac. Identification of $\mathrm{pH}$-zone refining counter-current chromatography pure fractions was carried out by using thermospray liquid chromatography-mass spectrometry (LC-MS) and by TLC co-elution experiments with reference alstonine samples provided by InterCEDD, Nsukka, Nigeria.

2.2.1. Drugs. Clozapine was purchased from Sigma Chemical Co. (St Louis, MO, US), and haloperidol was used as commercial Haldol (Janssen Farmacêutica Ltda, SP, Brazil). Clozapine was solubilized in $\mathrm{HCl}(0.1 \mathrm{~N})$ and its $\mathrm{pH}$ adjusted to 6.0 with $\mathrm{NaOH} 0.5 \mathrm{~N}$; alstonine and haloperidol were diluted in water. All drugs were administered intraperitoneally (ip) in a volume of $0.1 \mathrm{~mL} / 10 \mathrm{~g}$ of body weight.

2.2.2. Animals. Experiments were performed using male (CF1) adult albino mice, received from Fundação Estadual de Produção e Pesquisa em Saúde (FEPPS) at 2 months of age $(40-45 \mathrm{~g})$. Animals were maintained in our own animal facility under controlled environmental conditions $(22 \pm$ $1{ }^{\circ} \mathrm{C}, 12 \mathrm{~h}$-light/dark cycle, free access to food (Nuvilab CR1) and water), for at least 2 weeks before the experiments.

The project was approved by the University ethics committee (approval \#2007706) and all procedures were carried out in accordance with institutional policies on the handling of experimental animals. 
2.2.3. Brain Amines HPLC-ED Determination. Animals $(n=$ 10) received ip saline or alstonine $1.0 \mathrm{mg} \mathrm{kg}^{-1}$, and $30 \mathrm{~min}$ later were sacrificed by decapitation. Brains were rapidly removed and dissected over dry ice; striatum and frontal cortex were removed, weighed and immediately stored in liquid nitrogen. Not later than a week following sample collections, tissues were homogenized in $0.1 \mathrm{M}$ perchloric acid by manual sonication. DA and its metabolites dihydroxyphenylacetic acid (DOPAC) and homovanillic acid (HVA), as well as 5HT and its metabolite 5-hydroxyindole acetic acid (5-HIAA) were measured by reverse-phase high performance liquid chromatography (HPLC) with electrochemical detection, as described by Felicio et al. [20]. Briefly, the HPLC-ED system (model 6A; Shimatzu, Kyoto, Japan) consisted of a C-18 column (Shimpak; ODS, Kyoto, Japan), an electrochemical detector (model 6A; Shimatzu), a sample injector (valve for $20 \mu \mathrm{l}$ ), and an integrator (model 6A Chromatopac; Shimatzu). Dihydroxybenzylamine (DHBA) was used as the internal standard, and peak areas of external standard were used to quantify the sample peaks. The time for each sample was $28 \mathrm{~min}$. Values are expressed as $\mathrm{ng} / \mathrm{g}$ tissue weight. The detection limit was $0.002 \mathrm{ng}$ for DA, DOPAC, 5-HT, and 5HIAA, and 0.02 ng for HVA.

2.2.4. Glycaemia. Experiments were conducted between 9 a.m. and 12 midday. Groups of mice $(n=5-9)$ were treated ip with saline, clozapine ( 2.0 and $\left.10.0 \mathrm{mg} \mathrm{kg}^{-1}\right)$, and alstonine $\left(0.5\right.$ and $\left.1.0 \mathrm{mg} \mathrm{kg}^{-1}\right)$. Food and water were withdrawn immediately before treatments and glucose measurements were taken before and 3 hours after drug administration [7], with a glucometer (Accu-Chek Active Roche), using a blood drop drawn from the tail.

2.2.5. Body Weight. Mice $(n=8-10)$ were treated ip for 6 days with saline, haloperidol $\left(0.25 \mathrm{mg} \mathrm{kg}^{-1}\right)$, clozapine $\left(2.0 \mathrm{mg} \mathrm{kg}^{-1}\right)$ or alstonine $\left(0.5\right.$ and $\left.1.0 \mathrm{mg} \mathrm{kg}^{-1}\right)$. The body weight was measured daily between 12 a.m and 1 p.m.

2.2.6. Prolactin (PRL) Levels. Groups of mice $(n=6-$ 8) were treated with ip injection of saline, haloperidol $\left(0.25 \mathrm{mg} \mathrm{kg}^{-1}\right)$, clozapine $\left(2.0 \mathrm{mg} \mathrm{kg}^{-1}\right)$ or alstonine $\left(1.0 \mathrm{mg} \mathrm{kg}^{-1}\right)$. Animals were decapitated 30 minutes after treatments; the blood was collected and centrifuged for 10 minutes at $5000 \mathrm{rpm}$ and serum was stored at $-20^{\circ} \mathrm{C}$ until assayed. Plasma PRL levels were measured in duplicate by radioimmunoassay (RIA), using materials provided by NIADDK (Bethesda, MD, USA). The intra- and inter-assay coefficients of variation were $6 \%$ and $8 \%$, respectively [21].

2.2.7. Statistical Analysis. HPLC data were evaluated by independent $t$-test. Group differences in glucose and prolactin levels were analyzed by one-way ANOVA, followed by Duncan; pre and post drug glucose levels were analyzed by paired $t$-test. ANOVA with repeated measures followed by Duncan was used to evaluate weight gain. $P$-value $<.05$ was considered significant.

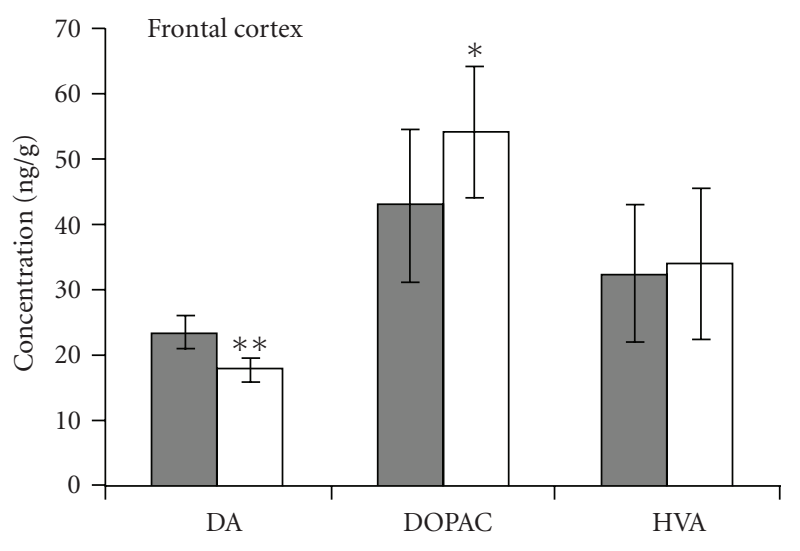

(a)

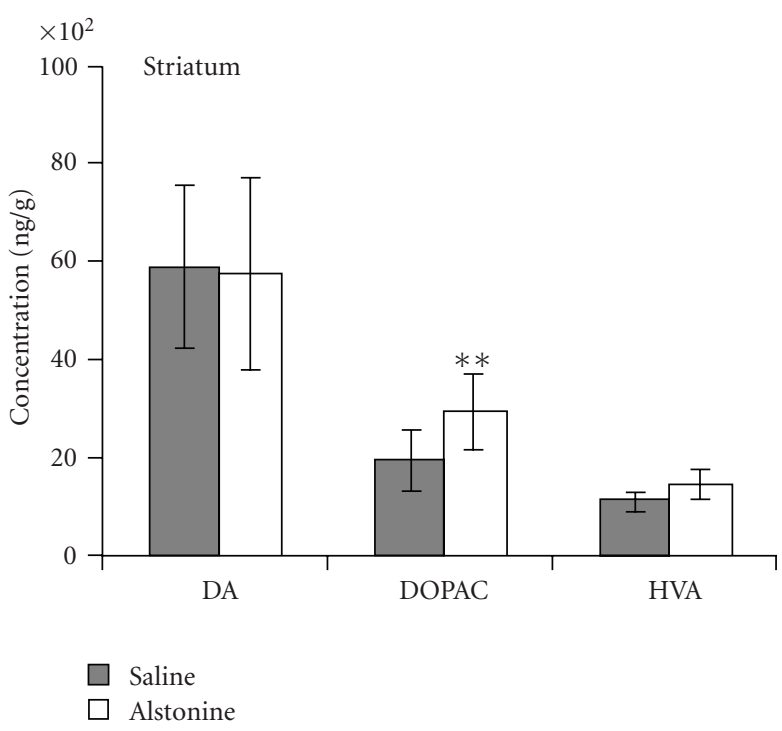

(b)

FIgure 2: Dopamine (DA) and its metabolites (DOPAC and HVA) in mouse frontal cortex (a) and in striatum (b) Mean \pm SD. ${ }^{*} P<$ $.05,{ }^{* *} P<.01$ when compared with saline, Independent $t$-test.

\section{Results}

The effects of alstonine on brain amines are shown in Figures 2 and 3. DA levels were decreased $(t=4.96, P<.01)$ in frontal cortex (Figure 2(a)), with a concomitant increase in DOPAC $(t=-2.22, P<.05)$ and no change in HVA. DOPAC levels were also increased $(t=-3.62, P<.01)$ in the striatum (Figure 2(b)), without changes in DA or HVA. 5HT levels were increased only in the frontal cortex $(t=-3.74, P<.05)$, whereas increases in 5-HIAA were seen in frontal cortex $(t=$ $-2.68, P<.01$, Figure $3(\mathrm{a}))$ and striatum $(t=-2.5, P<.05$, Figure 3(b)).

In control animals, as expected, a fasting-induced decrease in glucose levels was observed $(t=4.52, P<.01)$. The fasting-induced hypoglycaemia was absent with both clozapine and alstonine treatments (Figure 4). No differences in body weight gain were observed among treatment groups (Figure 5). Haloperidol $\left(0.25 \mathrm{mg} \mathrm{kg}^{-1}\right)$ markedly increased $(F(3,23)=12.78, P<.01)$ prolactin levels, whereas 


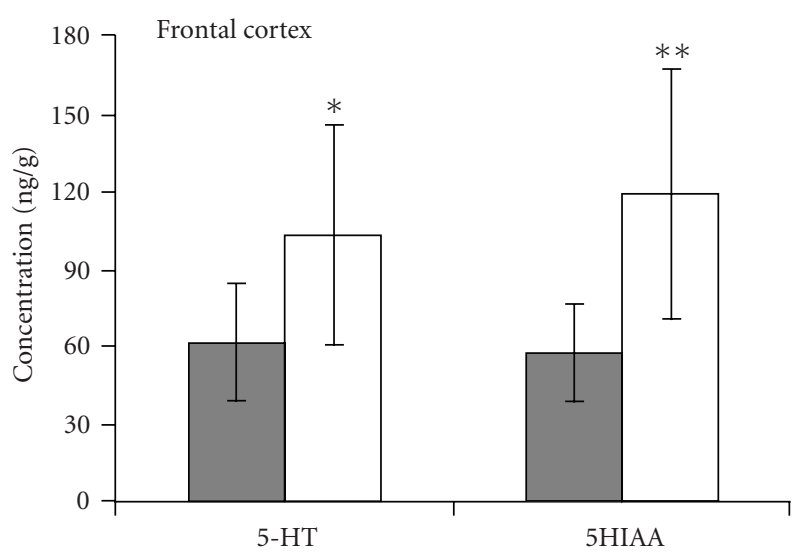

(a)

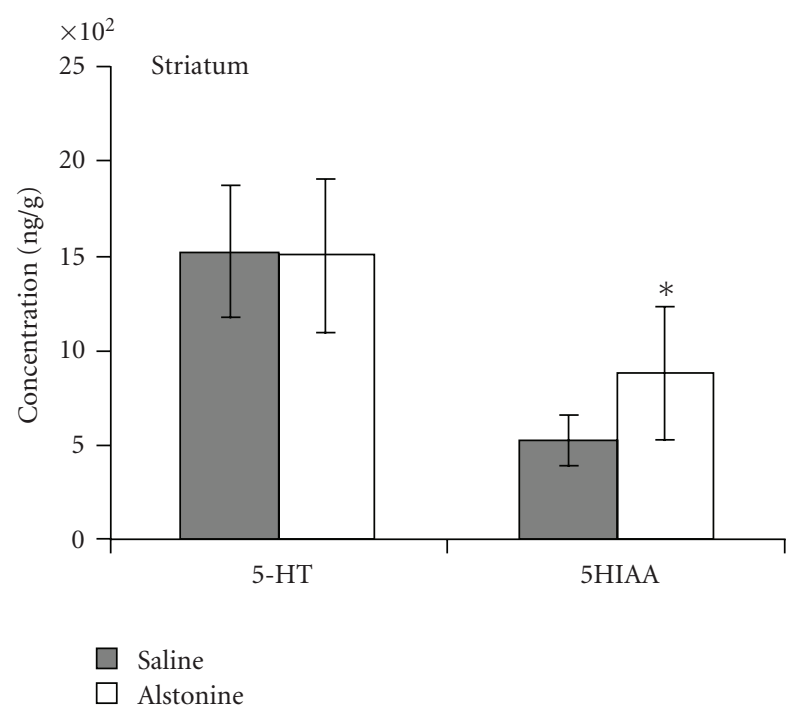

(b)

Figure 3: Serotonin (5-HT) and its metabolite (5HIAA) in mouse frontal cortex (a) and in striatum (b) Mean \pm SD. ${ }^{*} P<.05$, ${ }^{* *} P<$ .01 when compared with saline, Independent $t$-test.

clozapine $\left(2.0 \mathrm{mg} \mathrm{kg}^{-1}\right)$ and alstonine $\left(1.0 \mathrm{mg} \mathrm{kg}^{-1}\right)$ did not (Figure 6).

\section{Discussion}

Improving the effectiveness of antipsychotics appears to require proper and specific modulation of the various DA pathways. For instance, lessened extrapyramidal symptoms and amelioration of negative symptoms observed with newer agents is thought to be consequent to differential effects on the striatum and frontal cortex, respectively [10].

Although the behavioural profile of alstonine appears to be closer to that of newer rather than older antipsychotics, it nevertheless differs from clozapine in its ability to reverse MK801-induced hyperlocomotion [15] and social deficit [16], and by lacking epileptogenic properties [22]. An

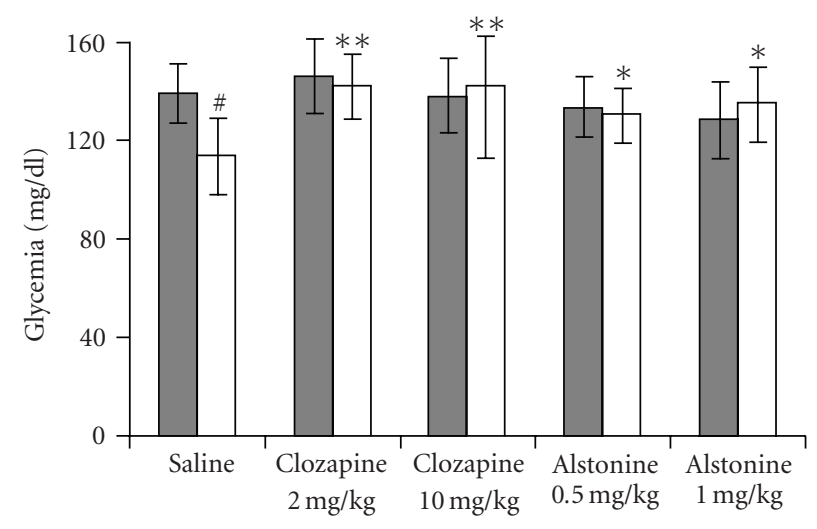

$$
\begin{aligned}
& \square \text { Pre } \\
& \square \text { Post }
\end{aligned}
$$

Figure 4: Effects of alstonine and clozapine on glucose levels. Mean \pm SD ${ }^{\#} P<.01$ compared with pre-drug, Paired $t$-test. ${ }^{*} P<.05$, ${ }^{* *} P<.01$ compared with saline post-drug, ANOVA/Duncan.

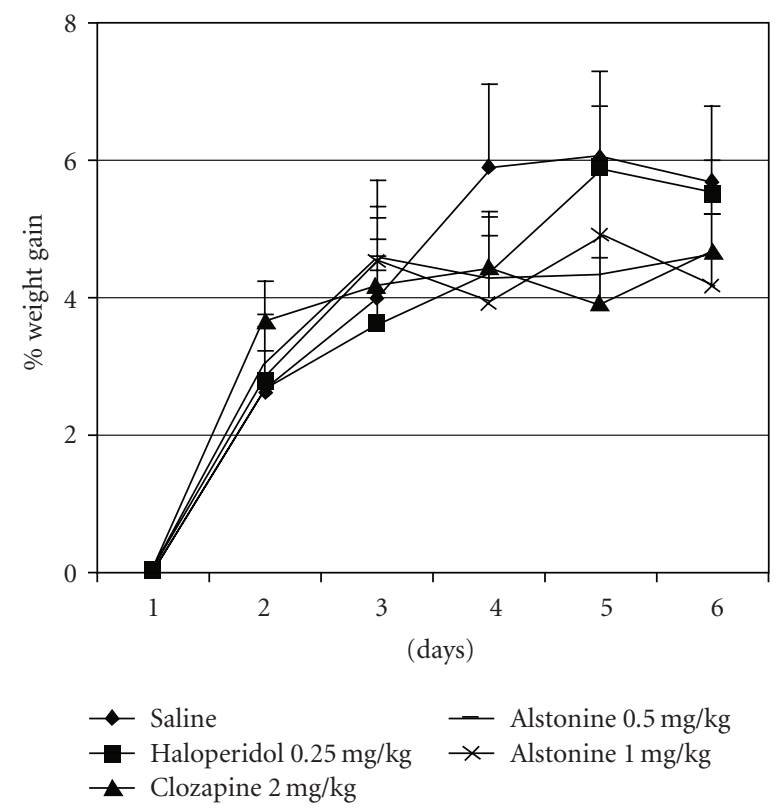

Figure 5: Body weight gain of mice treated with alstonine, haloperidol and clozapine. $n=8-10$. Mean + SD, ANOVA with repeated measures/Duncan.

unusual mechanism of action for alstonine is also here suggested by its effects on levels of DA in frontal cortex and striatum. Lack of changes in HVA levels suggests unchanged DA metabolism at the synaptic level, whereas increases in DOPAC levels suggests augmented intraneuronal catabolism.

DOPAC levels are accepted as a reliable index of intraneuronal DA degradation $[23,24]$, resulting from intracellular monoamine oxidase (MAO) activity. However, increases in DOPAC could also result from increased activity of the membrane transporter DAT, or even from the inhibition of the vesicular transporter VMAT2. All of these alternatives would eventually modulate DA availability at the synaptic 


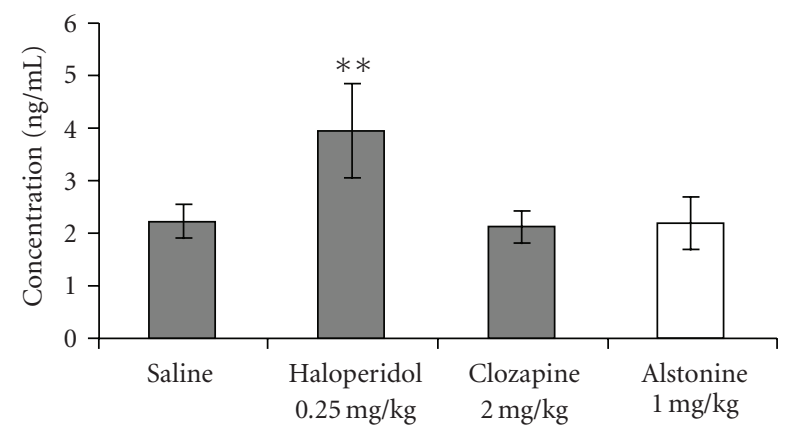

FIGURE 6: Effects of alstonine, haloperidol and clozapine on prolactin levels. Mean $\pm \mathrm{SD}$. ${ }^{* *} P<.01$ when compared with saline. ANOVA/Duncan.

level. The observed decrease in DA levels in the frontal cortex may not be significant behaviourally since we have recently shown that alstonine increased social interaction and prevented MK801 social withdrawal in mice [16], two accepted mouse models for behavioral equivalents of negative-like symptoms. Although only MAO or DAT inhibitor drugs are currently known, a direct effect of alstonine on these targets can not be ruled out at this point. Ongoing auto-radiography experiments will be useful to clarify this issue. In any case, a diminished DA availability at the synaptic level is consistent with alstonine's ability to counteract amphetamine-induced stereotypy and/or prevent lethality in amphetamine-treated grouped mice [14]. Although at this point it remains a matter of speculation, such an unusual neurochemical profile could open up innovative scenarios for antipsychotics and requires further scrutiny by specific experiments.

The HPLC analysis also shows that alstonine induced increases in 5HT levels in frontal cortex, and of 5HIAA in frontal cortex and striatum. The suggestion that alstonine acts as a $5 \mathrm{HT}_{2 \mathrm{~A}, \mathrm{C}}$ inverse agonist [15] is compatible with $5 \mathrm{HT}$ and 5HIAA increases, since pre-synaptic $5 \mathrm{HT}_{2 \mathrm{~A}, \mathrm{C}}$ receptors modulate $5 \mathrm{HT}$ release. $5 \mathrm{HT}$ modulation is considered to be central to the differential profile of newer antipsychotics, and dopamine modulation by serotonin is now generally accepted $[11,25-27] .5 \mathrm{HT}_{1 \mathrm{~A}}$ and $5 \mathrm{HT}_{2 \mathrm{~A}}$ receptors stimulate $\mathrm{DA}$ release in the cortex, whereas $5 \mathrm{HT}_{2} \mathrm{C}$ receptors may inhibit DA in the ventral tegmental area; it has been suggested that these combined properties could balance the DA system to the benefit of the management of schizophrenic symptoms [11].

It has been recognized that amino acid neurotransmitters may play a significant role in schizophrenia [28]. Although the anxiolytic effects of astonine were not modified by previous administration of picrotoxine $\left(\mathrm{GABA}_{\mathrm{A}}\right.$ antagonist), alstonine prevents the emergence of MK80-induced hyperlocomotion and social withdraw $[15,16]$. Given that alstonine does not seem to interfere directly with $\left[{ }^{3} \mathrm{H}\right]$ glutamate release by cortical synaptosomes [29], the data is rather consistent with an indirect glutamate modulation, since $5-\mathrm{HT}_{2}$ receptores are known to modulate NMDA glutamatergic transmission [30, 31]. Further studies are needed to better clarify the effects of alstonine on glutamate and GABA neurotransmission, and/or the role of these receptors on the amine changes induced by alstonine.

An extensive clinical trial comparing classical and atypical antipsychotics (known as CATIE) pointed to weight gain and hyperglycaemia as major causes of discontinuing therapy with the newer drugs [4]. Although treatment periods longer than those used here would have to be analyzed, neither alstonine nor clozapine or haloperidol altered mouse weight gain with doses effective in relevant behavioural mouse models. The precise mechanism by which antipsychotics alter glycemia is not completely clear. However, a number of candidates have been suggested such as $\mathrm{H}_{1}$ histamine receptors, $5 \mathrm{HT}_{2 \mathrm{C}}$ receptors, $\mathrm{M}_{3}$ muscarinic receptors, $\alpha_{2}$ adrenergic receptors and the inhibition of glucose transporters (GLUT) [7, 32]. Animal models of hyperglycemia appear to have a good correlation with clinically induced diabetes, and it is noticeable that not only atypical agents but also by some classic antipsychotic like chlorpromazine and perphenazine produce hyperglycemia in mice [32]. The fasting period used in this study induces a clear fall in the glycaemia levels of control animals, a drop absent in alstonine- and clozapine-treated mice. The data suggest that alstonine may share with atypical antipsychotics, such as clozapine, olanzapine and quetiapine, the unwanted changes in glucose metabolism. The exact mechanism by which such alterations occur requires explanation.

Relevant to adherence to treatment, a clear correlation exists between elevated PRL levels and DA D2 receptor occupancy by classical antipsychotics in the tuberoinfundibular pathway [2]. Although doses of antipsychotics used in rodents are usually much higher than those used in schizophrenic patients $[7,33,34]$ there is a similar pattern of antipsychotic-induced prolactin release [35].

Different from haloperidol, alstonine and clozapine did not alter PRL levels, further confirming the atypical profile of the former and reinforcing its differential effects on the dopaminergic pathways.

In conclusion, this study reinforces the opinion that a comprehensive understanding of the neurochemical basis of alstonine's seemingly innovative profile as an antipsychotic may open new avenues to developing newer medications useful for the treatment of schizophrenic patients. Considering the gaps in the understanding of schizophrenia and the complexity of its neurochemical basis, this study underpins the value of traditional medical systems in unveiling original drugs.

\section{Funding}

FINEP research grant "Rede Instituto Brasileiro de Neurociência (IBN-Net)” \# 01.06.0842-00.

\section{Acknowledgments}

The authors are grateful to CNPq and CAPES for fellowships, and Poli Mara Spritzer and Janine Costa Ivo for technical assistance in PRL analysis. 


\section{References}

[1] S. Miyamoto, G. E. Duncan, C. E. Marx, and J. A. Lieberman, "Treatments for schizophrenia: a critical review of pharmacology and mechanisms of action of antipsychotic drugs," Molecular Psychiatry, vol. 10, no. 1, pp. 79-104, 2005.

[2] M. T. Compton and A. H. Miller, "Antipsychotic-induced hyperprolactinemia and sexual dysfunction," Psychopharmacology Bulletin, vol. 36, no. 1, pp. 143-164, 2002.

[3] J. Kane, G. Honigfeld, J. Singer, and H. Meltzer, "Clozapine for the treatment-resistant schizophrenic. A double-blind comparison with chlorpromazine," Archives of General Psychiatry, vol. 45, no. 9, pp. 789-796, 1988.

[4] J. A. Lieberman, T. Scott Stroup, J. P. McEvoy et al., "Effectiveness of antipsychotic drugs in patients with chronic schizophrenia," The New England Journal of Medicine, vol. 353, no. 12, pp. 1209-1223, 2005.

[5] D. B. Allison, J. L. Mentore, M. Heo et al., "Antipsychoticinduced weight gain: a comprehensive research synthesis," American Journal of Psychiatry, vol. 156, no. 11, pp. 1686-1696, 1999.

[6] D. S. Dwyer, "Model of the 3-D structure of the GLUT3 glucose transporter and molecular dynamics simulation of glucose transport," Proteins, vol. 42, no. 4, pp. 531-541, 2001.

[7] D. S. Dwyer and D. Donohoe, "Induction of hyperglycemia in mice with atypical antipsychotic drugs that inhibit glucose uptake," Pharmacology Biochemistry and Behavior, vol. 75, no. 2, pp. 255-260, 2003.

[8] S. H. Schultz, S. W. North, and C. G. Shields, "Schizophrenia: a review," American Family Physician, vol. 75, no. 12, pp. 18211829, 2007.

[9] A. N. Elias and H. Hofflich, "Abnormalities in glucose metabolism in patients with schizophrenia treated with atypical antipsychotic medications," American Journal of Medicine, vol. 121, no. 2, pp. 98-104, 2008.

[10] D. M. Gardner, R. J. Baldessarini, and P. Waraich, "Modern antipsychotic drugs: a critical overview," Canadian Medical Association Journal, vol. 172, no. 13, pp. 1703-1711, 2005.

[11] K. D. Alex and E. A. Pehek, "Pharmacologic mechanisms of serotonergic regulation of dopamine neurotransmission," Pharmacology and Therapeutics, vol. 113, no. 2, pp. 296-320, 2007.

[12] A. Abi-Dargham, "Do we still believe in the dopamine hypothesis? New data bring new evidence," International Journal of Neuropsychopharmacology, vol. 7, supplement 1, pp. S1-S5, 2004.

[13] L. Costa-Campos, E. Elisabetsky, D. R. Lara et al., "Antipsychotic profile of alstonine: ethnopharmacology of a traditional Nigerian botanical remedy," Anais da Academia Brasileira de Ciências, vol. 71, no. 2, pp. 189-201, 1999.

[14] L. Costa-Campos, D. R. Lara, D. S. Nunes, and E. Elisabetsky, "Antipsychotic-like profile of alstonine," Pharmacology Biochemistry and Behavior, vol. 60, no. 1, pp. 133-141, 1998.

[15] L. Costa-Campos, S. C. Dassoler, A. P. Rigo, M. Iwu, and E. Elisabetsky, "Anxiolytic properties of the antipsychotic alkaloid alstonine," Pharmacology Biochemistry and Behavior, vol. 77, no. 3, pp. 481-489, 2004.

[16] V. de Moura Linck, A. P. Herrmann, G. C. Goerck et al., "The putative antipsychotic alstonine reverses social interaction withdrawal in mice," Progress in Neuropsychopharmacology and Biological Psychiatry, vol. 32, no. 6, pp. 1449-1452, 2008.

[17] C. O. Okunji, M. M. Iwu, Y. Ito, and P. L. Smith, "Preparative separation of indole alkaloids from the rind of Picralima nitida
(Stapf) T. Durand \& H. Durand by $\mathrm{pH}$-zone-refining countercurrent chromatography," Journal of Liquid Chromatography and Related Technologies, vol. 28, no. 5, pp. 775-783, 2005.

[18] Y. Ito, "High-speed countercurrent chromatography," in HighSpeed Countercurrent Chromatography Chemical Analysis, Y. Ito and W. D. Conway, Eds., pp. 225-263, Wiley-Interscience, New York, NY, USA, 1996.

[19] K. Shinomiya, J. M. Menet, H. M. Fales, and Y. Ito, "Studies on a new cross-axis coil planet centrifuge for performing countercurrent chromatography. 1. Design of the apparatus, retention of the stationary-phase, and efficiency in the separation of proteins with polymer phase systems," Journal of Chromatography, vol. 644, pp. 215-229, 1993.

[20] L. F. Felicio, J. C. Florio, L. H. Sider, P. E. Cruz-Casallas, and R. S. Bridges, "Reproductive experience increases striatal and hypothalamic dopamine levels in pregnant rats," Brain Research Bulletin, vol. 40, no. 4, pp. 253-256, 1996.

[21] M. C. Doretto, M. Oliveira-e-Silva, D. L. Ferreira-Alves, S. G. Pires, N. Garcia-Cairasco, and A. M. Reis, "Effect of lactation on the expression of audiogenic seizures: association with plasma prolactin profiles," Epilepsy Research, vol. 54, no. 2-3, pp. 109-121, 2003.

[22] L. Costa-Campos, M. Iwu, and E. Elisabetsky, "Lack of proconvulsant activity of the antipsychotic alkaloid alstonine," Journal of Ethnopharmacology, vol. 93, pp. 307-310, 2004.

[23] B. H. C. Westerink, "Sequence and significance of dopamine metabolism in the rat brain," Neurochemistry International, vol. 7, no. 2, pp. 221-227, 1985.

[24] D. J. Haleem, F. Batool, N. H. Khan et al., "Differences in the effects of haloperidol and clozapine on brain serotonin and dopamine metabolism and on tests related to extrapyramidal functions in rats," Medical Science Monitor, vol. 8, no. 9, pp. BR354-BR361, 2002.

[25] G. Lucas and U. Spampinato, "Role of striatal serotonin(2A) and serotonin(2C) receptor subtypes in the control of in vivo dopamine outflow in the rat striatum," Journal of Neurochemistry, vol. 74, no. 2, pp. 693-701, 2000.

[26] V. Di Matteo, M. Cacchio, C. Di Giulio, and E. Esposito, "Role of serotonin2C receptors in the control of brain dopaminergic function," Pharmacology Biochemistry and Behavior, vol. 71, no. 4, pp. 727-734, 2002.

[27] P. De Deurwaerdère, S. Navailles, K. A. Berg, W. P. Clarke, and U. Spampinato, "Constitutive activity of the serotonin2C receptor inhibits in vivo dopamine release in the rat striatum and nucleus accumbens," Journal of Neuroscience, vol. 24, no. 13, pp. 3235-3241, 2004.

[28] A. Carlsson, N. Waters, S. Holm-Waters, J. Tedroff, M. Nilsson, and M. L. Carlsson, "Interactions between monoamines, glutamate, and GABA in schizophrenia: new evidence," Annual Review of Pharmacology and Toxicology, vol. 41, pp. 237-260, 2001.

[29] E. Elisabetsky and L. Costa-Campos, "The alkaloid alstonine: a review of its pharmacological properties," Evidence-Based Complementary and Alternative Medicine, vol. 3, no. 1, pp. 3948, 2006.

[30] V. L. Arvanov and R. Y. Wang, "A selective 5-HT2A receptor antagonist and a potential antipsychotic drug, facilitates $\mathrm{N}$ methyl-d-aspartatereceptor mediated neurotransmission in the medial prefrontal cortical neurons in vitro," Neuropsychopharmacology, vol. 18, no. 3, pp. 197-209, 1998.

[31] C. F. Spurney, S. M. Baca, A. M. Murray, G. E. Jaskiw, J. E. Kleinman, and T. M. Hyde, "Differential effects of haloperidol and clozapine on ionotropic glutamate receptors in rats," Synapse, vol. 34, no. 4, pp. 266-276, 1999. 
[32] Y. E. Savoy, M. A. Ashton, M. W. Miller et al., "Differential effects of various typical and atypical antipsychotics on plasma glucose and insulin levels in the mouse: Evidence for the involvement of sympathetic regulation," Schizophrenia Bulletin, vol. 36, no. 2, pp. 410-418, 2010.

[33] M. J. Millan, F. Loiseau, A. Dekeyne, A. Gobert, G. Flik, T. I. Cremers et al., "S33138 (N-[4-[2-[(3aS,9bR)-8-cyano1,3a,4,9b-tetrahydro[1] benzopyrano[3,4-c]pyrrol-2(3H)-yl)ethyl]phenyl-acetamide), a preferential dopamine D3 versus D2 receptor antagonist and potential antipsychotic agent: III. Actions in models of therapeutic activity and induction of side effects," Journal of Pharmacology and Experimental Therapeutics, vol. 324, pp. 1212-1226, 2008.

[34] J. P. Rung, A. Carlsson, K. R. Markinhuhta, and M. L. Carlsson, "(+)-MK801 induced social withdrawal in rats; a model for negative symptoms of schizophrenia," Progress in Neuro-Psychopharmacology \& Biological Psychiatry, vol. 29, pp. 827-832, 2005.

[35] C. Rourke, K. R. Starr, C. Reavill, S. Fenwick, K. Deadman, and D. N. C. Jones, "Effects of the atypical antipsychotics olanzapine and risperidone on plasma prolactin levels in male rats: a comparison with clinical data," Psychopharmacology, vol. 184, no. 1, pp. 107-114, 2006. 


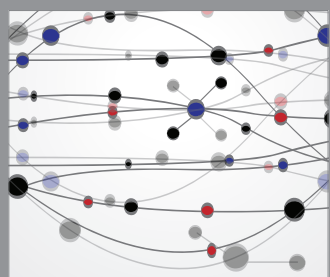

The Scientific World Journal
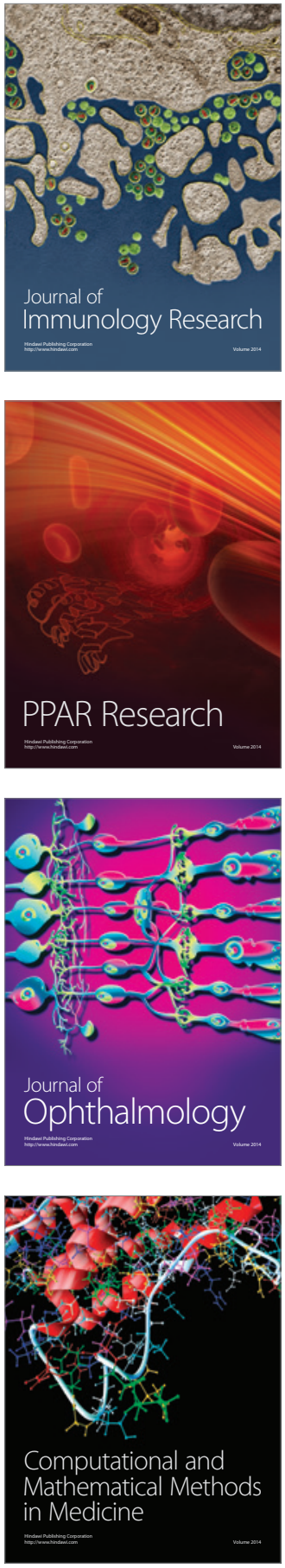

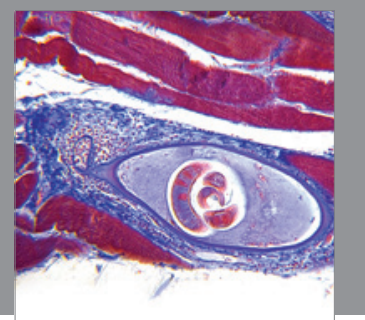

Gastroenterology

Research and Practice
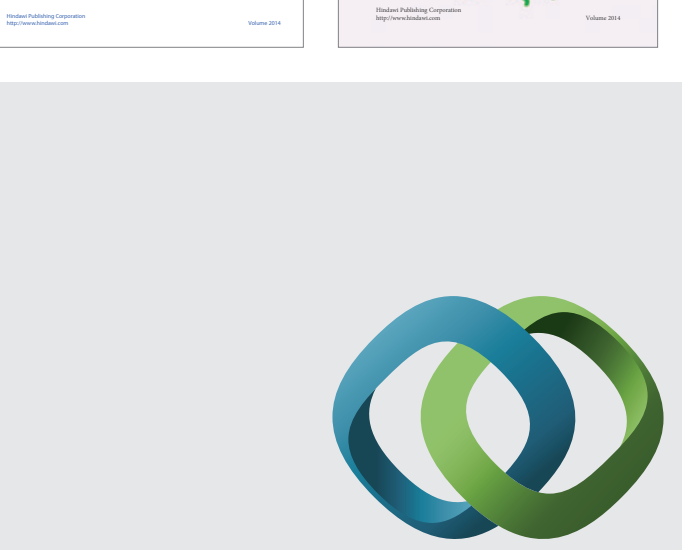

\section{Hindawi}

Submit your manuscripts at

http://www.hindawi.com
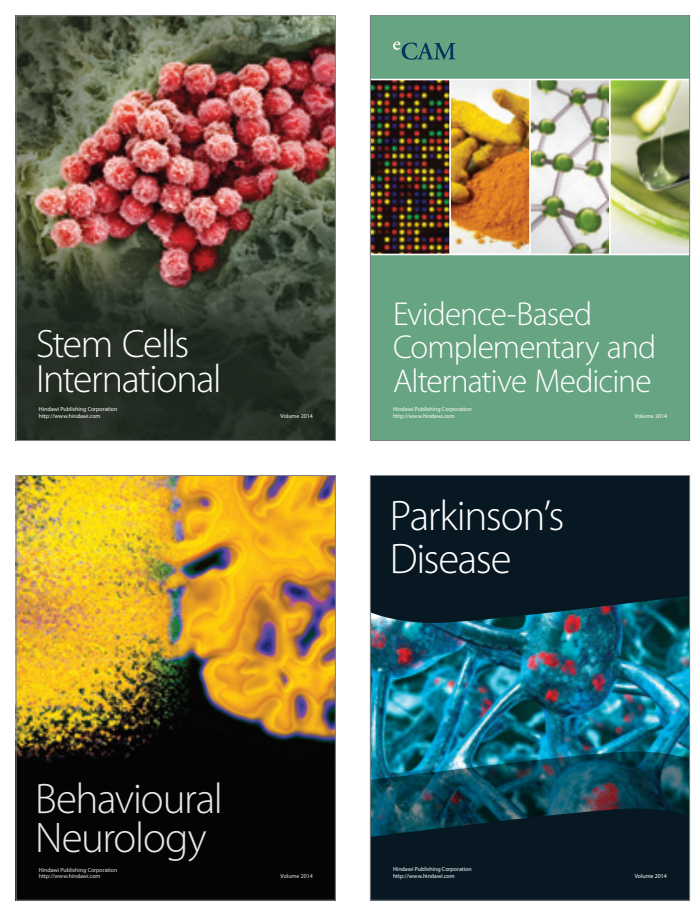

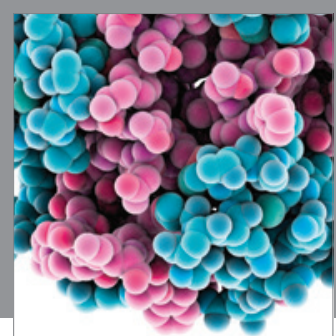

Journal of
Diabetes Research

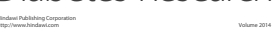

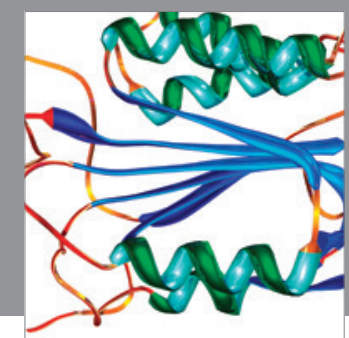

Disease Markers
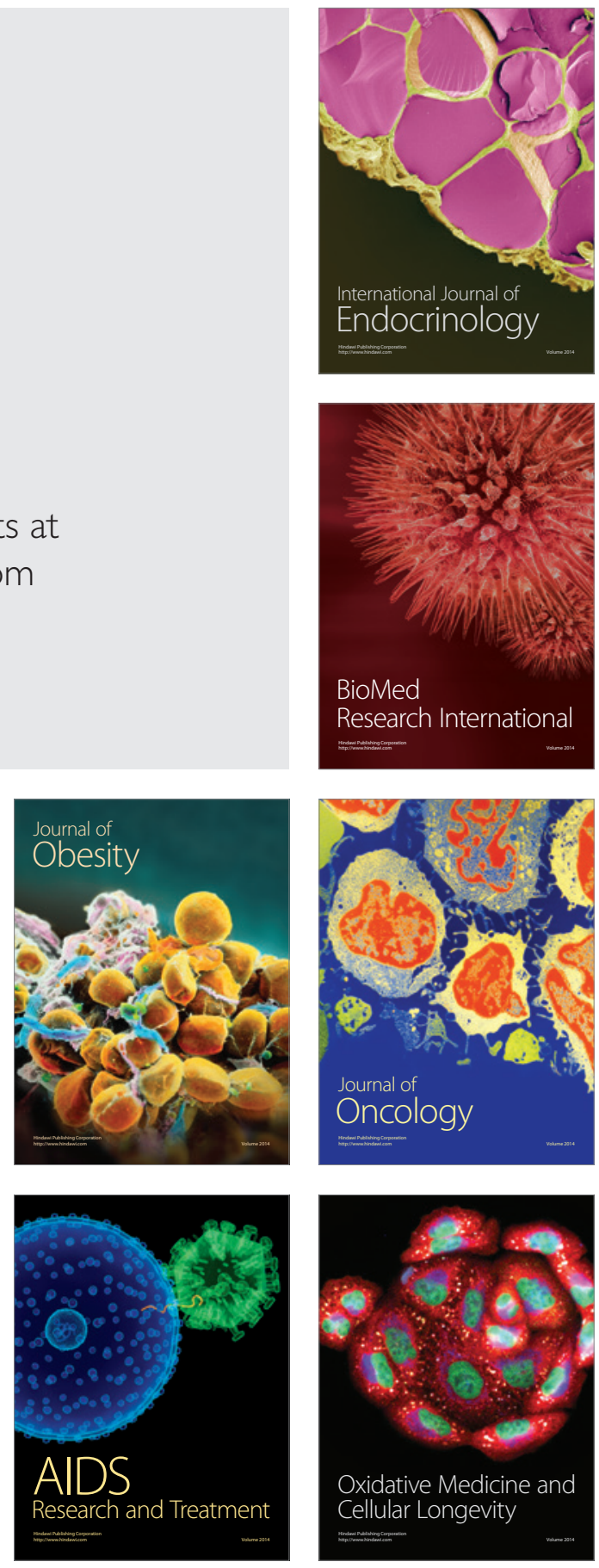